\title{
Long Non-Coding RNAs in Multiple Myeloma
}

\author{
Lucia Nobili ${ }^{(1)}$, Domenica Ronchetti, Luca Agnelli ${ }^{\circledR}$, Elisa Taiana, Cristina Vinci and \\ Antonino Neri * \\ Department of Oncology and Hemato-Oncology, University of Milan, and Hematology, \\ Fondazione Ca' Granda IRCCS Policlinico, 20122 Milan, Italy; lucia.nobili@unim.it (L.N.); \\ domenica.ronchetti@unimi.it (D.R.); luca.agnelli@unimi.it (L.A.); elisa.taiana@unimi.it (E.T.); \\ cristina.vinci@unimi.it (C.V.) \\ * Correspondence: antonino.neri@unimi.it; Tel.: +39-02-5032-0420
}

Received: 14 December 2017; Accepted: 26 January 2018; Published: 1 February 2018

\begin{abstract}
Multiple myeloma (MM) is an incurable disease caused by the malignant proliferation of bone marrow plasma cells, whose pathogenesis remains largely unknown. Although a large fraction of the genome is actively transcribed, most of the transcripts do not serve as templates for proteins and are referred to as non-coding RNAs (ncRNAs), broadly divided into short and long transcripts on the basis of a 200-nucleotide threshold. Short ncRNAs, especially microRNAs, have crucial roles in virtually all types of cancer, including $\mathrm{MM}$, and have gained importance in cancer diagnosis and prognosis, predicting the response to therapy and, notably, as innovative therapeutic targets. Long ncRNAs (lncRNAs) are a very heterogeneous group, involved in many physiological cellular and genomic processes as well as in carcinogenesis, cancer metastasis, and invasion. LncRNAs are aberrantly expressed in various types of cancers, including hematological malignancies, showing either oncogenic or tumor suppressive functions. However, the mechanisms of the related disease-causing events are not yet revealed in most cases. Besides emerging as key players in cancer initiation and progression, lncRNAs own many interesting features as biomarkers with diagnostic and prognostic importance and, possibly, for their utility in therapeutic terms as druggable molecules. This review focuses on the role of lncRNAs in the pathogenesis of MM and summarizes the recent literature.
\end{abstract}

Keywords: long non-coding RNAs (lncRNAs); multiple myeloma (MM); expression profiling; transcription regulation

\section{Introduction}

Multiple myeloma (MM) is a fatal malignant proliferation of antibody-secreting bone marrow (BM) plasma cells (PCs) that accounts for $10 \%$ of all hematological malignancies with an incidence in western countries of about 3-5 per 100,000. MM is characterized by an extensive clinical variety ranging from the presumed premalignant condition, called monoclonal gammopathy of undetermined significance (MGUS), to extramedullary myeloma and plasma cell leukemia (PCL) [1-3]. Despite the remarkable improvements in the treatment and patient care [4], MM remains an incurable disease.

MM shows a high genomic time- and phase-dependent instability and consequently a very complex karyotype that leads this plasma cell dyscrasia to more resemble solid than haematologic tumors $[1,5,6]$. Nearly half of MM tumors are hyperdiploid, associated with nonrandom trisomies of odd chromosomes. The remaining tumors are non-hyperdiploid and frequently associated with the constitutive activation of CCND1 (11q13), CCND3 (6p21), MAF (16q23), MAFB (20q11), or FGFR3/MMSET (4p16.3) genes consequent to chromosomal translocations involving the immunoglobulin heavy-chain locus (IGH) on chromosome 14q32. The mechanisms underlying this dichotomic pattern have not been elucidated yet. Hyperdiploid patients have a generally better prognosis, whereas the $t(4 ; 14)$ and $t(14 ; 16)$ translocations 
are associated with a poor prognosis, either under conventional or high-dose therapy. In addition, allelic imbalances of specific genomic regions, including 13q,17p13,1p,16q, 14q losses and 1q gains, are adversely linked to prognosis [5,6]. The high-risk chromosomal aberrations del $(17 \mathrm{p} 13), \mathrm{t}(4 ; 14)$, and 1q21 have been identified as adverse prognostic factors also in asymptomatic smoldering MM (SMM), independent of the tumor burden, whereas hyperdiploidy, contrary to active myeloma, seems to be an adverse prognostic factor in SMM [7]. Overall, transcriptional data have provided valuable information on the genes aberrantly expressed in MM, further supporting their high biological heterogeneity and showing their promising prognostic role [8].

During the last two decades of research, thanks to the impressive development and application of high-throughput sequencing techniques, it has been demonstrated that, although a large fraction of the human genome is actively transcribed $[9,10]$, non-coding RNAs (ncRNAs), namely the RNA fraction not translated into canonical functional proteins, account for the majority of transcripts. Increasing evidence suggests their huge impact on several molecular mechanisms: in particular, the roles of ncRNAs in supporting cellular homeostasis and gene expression regulation and in governing different pathologies are recently emerging.

According to their size, ncRNAs have been arbitrarily categorized into short and long ncRNAs (lncRNAs), the latter being longer than 200 nucleotides. Short ncRNAs can be further subdivided into various categories, including microRNAs (miRNAs), small interfering RNAs, PIWI-associated RNAs and small nucleolar RNAs. Dysregulated short ncRNAs, especially miRNAs, are known to have important functions in virtually all types of cancer, including MM. Further, miRNA profiling has assumed a crucial value in tumor diagnosis and prognosis and in predicting the response to therapy [11]. Notably, miRNAs have also gained importance as innovative therapeutic targets in cancer, including MM [12-14].

LncRNAs are a heterogeneous group representing more than half of the mammalian non-coding transcriptome. They participate in various biological processes, such as transcriptional gene regulation, maintenance of genomic integrity, X-chromosome inactivation, genomic imprinting, cell differentiation, and development. LncRNAs are transcribed from introns, exons, intergenic or intra-genic regions, promoter regions, $3^{\prime}$ - and $5^{\prime}$-UTRs; therefore, they may represent intronic, intergenic, bidirectional, and antisense- or sense-overlapping sequences [15,16]. The catalog of known human lncRNA genes and transcripts has been growing impressively over the last few years and is still evolving. The largest repositories currently contain more than 60,000 human annotated lncRNA genes (e.g., 65,694 LNCpedia v4.1; 96,308 Noncode v5.0), with many loci generating multiple transcripts. Such a discrepancy is mainly attributable to the wide or stringent criteria used to include sequences based on RNA-sequencing studies predictions $[17,18]$.

Not greatly different from mRNAs as it regards structure and biogenesis, IncRNAs can be polyadenylated and may operate in either nuclear or cytoplasmic fractions. Their expression is developmentally regulated and it is restricted to specific cell or tissue types to a greater extent than mRNA [15]. The adaptability due to their secondary structure allows lncRNAs to form binding sites for the interaction with proteins, DNA, and other RNA molecules. Thanks to specific substructures, lncRNAs can then function as guides, tethers, decoys, and scaffolds. LncRNAs can regulate gene expression at three levels, specifically, the transcriptional, post-transcriptional, and chromatin modification levels [16,19-24]. Although the mechanisms underlying the function of most lncRNAs are not fully understood, the deregulation of distinct lncRNAs has been reported to promote tumor formation, progression, and metastasis in many types of cancer, including hematologic malignancies $[20,21]$. Interestingly, because of their presence in body fluids, including urine and blood, although at a low level of expression, circulating cell-free lncRNAs are promising putative non-invasive diagnostic and prognostic biomarkers in cancer patients [25].

Even though it is still in its beginnings, the knowledge of the role of lncRNAs in MM is progressively expanding. In this review, we provide a compendium of the lncRNAs reported to be deregulated in MM and, therefore, putatively implicated in its pathogenesis and clinical outcome. 


\section{LncRNAs in Multiple Myeloma}

\subsection{MALAT1}

The expression of MALAT1 (metastasis-associated lung adenocarcinoma transcript 1), a putative oncogenic lncRNA transcribed from chromosome 11q13 and overexpressed in several solid tumors [26,27], was firstly investigated by Cho et al. [28] in BM mononuclear cells from MM patients with different disease status at diagnosis, showing its significant overexpression compared to normal controls. Moreover, patients who relapsed or had disease progression showed a significant increased expression of MALAT1. These findings were further supported by Ronchetti et al. investigating, by expression microarray, a large cohort of patients encompassing all the major different forms of PC dyscrasias: notably, an association was found between MALAT1 upregulation and molecular pathways involved in cell cycle regulation, p53-mediated DNA damage response, and mRNA maturation processes [29]. More recently, other groups found high expression levels of MALAT1 in BM mononuclear cells from untreated MM patients with different disease status, as well as in MM cell lines, along with a significant reduction of its expression in complete remission patients [30-32]. In the study from Gao et al. [30], the expression trend of MALAT1 strictly resembled that of the DNA-binding protein high mobility group box 1 (HMGB1), which acts as a mediator of autophagy in the cytoplasm. HMGB1 was previously found overexpressed in MM and shown to sustain the survival and proliferation of myeloma cells [33]. MALAT1 knockdown in MM cell lines and in a mouse model [30] reduced HMGB1 expression levels as well as the expression of Beclin-1 and LC3B, both related to autophagy. The direct binding between MALAT-1 and HMGB1 might be partially responsible for an increased ubiquitination and degradation of the protein. MALAT1 knockdown promoted also a significant reduction of viability and an increase of apoptosis in MM cells, whereas the combined HMGB1 overexpression was able to abolish all the mentioned effects. These findings suggest that MALAT1 favors autophagy in MM by upregulating HMGB1 expression, thus supporting its role in the suppression of apoptosis and the promotion of tumor cell survival. The induction of apoptosis in MALAT1-silenced cells might involve a down-regulation of cyclin D1 and cyclin E, the activation of caspase- 3 and caspase-9, the increased level of the pro-apoptotic protein BAX, and the decreased level of the anti-apoptotic protein BCL-2 [31]. Worth noting is also that MALAT1 has been recently linked with the extramedullary dissemination of MM, often developing after several chemotherapeutic interventions and associated with a worse prognosis: not only a substantially greater expression of MALAT1 was found in extramedullary MM, but even higher expression levels were shown in extramedullary PCs matched with the intramedullary ones from the same patients [32]. These findings extend previous data [29], thus suggesting a role for MALAT1 in extramedullary dissemination. This hypothesis was further supported by the correlation of higher MALAT1 expression with worse overall and progression-free survival (OS and PFS); in particular, MALAT1 expression showed an independent influence on PFS, suggesting a possible role in drug resistance [32]. Furthermore, the positive correlation between the expression levels of MALAT1 and heat shock protein $90 \mathrm{~s}$ (known to be induced in response to diverse cellular stress), together with the in vitro demonstration of MALAT1 upregulation after treatment with proteasome inhibitors and doxorubicin, suggested that MALAT1 overexpression might depend on, or at least be related to, the chemotherapeutic stress response [32].

Finally, MALAT1 was recently shown to be overexpressed in mesenchymal stromal cells (MSCs) from MM patients, which led to the transcriptional activation of the neighboring antisense protein-coding gene LTBP3 (latent TGF- $\beta$-binding protein) [34]. LTBP3 is acknowledged as a positive regulator of the activity of TGF- $\beta$, which may get involved in the inhibition of terminal osteoblastogenesis in MM [35]. Actually, it was demonstrated that MALAT1 recruits the transcription factor SP1 on the LTBP3 promoter, thus contributing to the increase of LTBP3 expression. Conversely, a significant reduction of LTBP3 transcription followed MALAT1 knockdown [34]. 


\subsection{MEG3}

MEG3 (maternally expressed gene 3) lncRNA, located at 14q32.2, is thought to act as a tumor suppressor through both p53-dependent and p53-independent mechanisms and to be controlled epigenetically at the expression level [36,37]. Studying the expression of MEG3 in MM, Benetatos et al. observed hypermethylation of the differentially methylated region (DMR) of the MEG3 promoter in about $60 \%$ of patients, which correlated with both disease stage and subtype [38]. Two-third of the patients with IgG MM and all of those with IgM exhibited the epigenetic alteration, whereas none of the patients with IgA had hypermethylated DMR. These findings led to suggest a possible involvement of $M E G 3$ lncRNA promoter hypermethylation and, consequently, of its reduced expression in MM tumorigenesis. Of interest, MSCs from MM patients (MM-MSCs) expressed MEG3 to a lesser degree than those from normal donors (ND-MSCs) throughout osteogenic differentiation [39]. Moreover, the overexpression of MEG3 was able to stimulate MM-MSCs to differentiate, while MEG3 knockdown had a negative effect on the osteogenesis of ND-MSCs. On the basis of experimental investigations, MEG3 promoted osteogenesis by targeting the transcription of BMP4 (bone morphogenetic protein 4), a gene member of the TGF family. Both MEG3 and BMP4 map to chromosome 14, albeit with divergent transcription orientation. MEG3 is supposed to interact directly with the transcription factor SOX2, triggering its separation from the $B M P 4$ promoter and then determining an increase of $B M P 4$ expression [39].

\subsection{CRNDE}

CRNDE (colorectal neoplasia differentially expressed), a lncRNA mapped at 16q12.2, was firstly recognized as upregulated in colorectal cancer [40]. Subsequently, the elevated expression of this IncRNA was found in the early stages of human development, in several solid tumors, as well as in leukemias and MM [41]. In their recent study, Meng et al. [42] found increased expression of CRNDE in MM cell lines and patients, associated with poor OS. CRNDE knockdown in U266 and RPMI-8226 cell lines inhibited proliferation and colony formation and led to increased apoptosis and cell cycle arrest in G0/G1 phase. The knockdown of CRNDE in U266 cells was associated with a considerable increment of miR-451 expression, otherwise downregulated in MM patients compared with normal controls. By means of bioinformatics analysis and dual-luciferase reporter assay, a putative complementary interaction between miR-451 and the 3'-UTR of CRNDE was shown. Furthermore, Meng et al. found a negative correlation of $C R N D E$ with miR-451 in MM patients, suggesting that $C R N D E$ might act in MM pathogenesis by negatively targeting miR-451. This hypothesis was reinforced by the observation that miR-451 inhibition was able to rescue the above described effects of CRNDE knockdown in U266 cell line, thus restoring the tumorigenesis of the cells [42].

\subsection{UCA1}

A possible prognostic impact of the expression level of lncRNA UCA1 (urothelial cancer associated 1) in MM was recently postulated by Sedlarikova et al. [43] in a study analyzing the expression of 83 candidate lncRNAs in BM PCs of newly diagnosed MM patients compared to normal BM PCs of healthy donors (HD). Specifically, of the 27 lncRNAs identified as differentially expressed in MM patients, UCA1 resulted significantly downregulated in MM samples compared to HD, also showing a negative and a positive correlation with albumin and monoclonal-Ig serum levels, respectively. Moreover, in MM patients higher levels of UCA1 correlated with poorer OS and the occurrence of 1q21 gain or $\mathrm{t}(4 ; 14)$ translocation, known unfavorable prognostic features of MM.

$U C A 1$, mapped at 19p13.12, was firstly identified as greatly expressed in bladder transitional cell carcinoma [44]. A link between UCA1 and the transcription factor CREB (cAMP response element-binding protein) was found in bladder cancer cells [45] indicating that UCA1 might influence cell cycle regulation by activating CREB via PI3K-AKT pathway. 


\subsection{OIP5-AS1}

Yang et al. discovered an inverse correlation between the high levels of miR-410 expression in newly diagnosed MM and lncRNA OIP5-AS1 (OIP5 antisense RNA 1), mapped on chromosome $15 q 15.1$ [46]. Experimental evidences indicated that OIP5-AS1 was able to inversely modulate the expression of miR-410 and its pro-oncogenic effects on cell proliferation, cell cycle progression, and apoptosis in NCI-H929 and RPMI-8226 cell lines. On the basis of the identification of KLF10 (Kruppel Like Factor 10), involved in PTEN-AKT signaling activation, as a direct downstream target of miR-410 in MM, it was further demonstrated the contribution of OIP5-AS1 in the KLF10-PTEN-AKT signaling pathway in MM cells, very likely through a negative regulation of miR-410. Overall, the loss of lncRNA OIP5-AS1 induced miR-410 accumulation in MM cells leading to cell proliferation, cell cycle progression, and apoptosis inhibition via the KLF10-PTEN-AKT signaling axis.

\section{IncRNA Expression Profiles in MM}

Studies investigating the global lncRNA expression in MM are still limited and based on microarray data. In particular, there are two different studies concerning the same publicly available microarray datasets including a large group of 559 MM patients, profiled onto GeneChip ${ }^{\circledR} 3^{\prime}$-in vitro transcription arrays querying the poly-A+ fraction of transcripts $[47,48]$. In the first investigation, Zhou et al. [47] examined a list of 2330 lncRNA by re-annotating such datasets and identified a four-lncRNA prognostic signature able to predict survival in MM patients. In particular, two lncRNAs, RP1-43E13.2 and RP4-803J11.2, are located on chromosome 1p and 1q, respectively, frequently lost or gained in MM and related with poor prognosis [6,49-51]. The second study, based on custom lncRNA-oriented annotation files of the same datasets, identified 176 lncRNAs able to clusterize patients into two groups with significant differences in terms of OS [48] and predict the patient's prognosis independently from $\beta 2$-microglobulin, albumin, and LDH serum levels.

Ronchetti et al. [29], by employing new-generation whole-transcript arrays, analyzed the global lncRNA expression profiles in a group of 259 patients, representative of all the main forms of PC dyscrasias, which included MGUS, asymptomatic SMM, truly overt and symptomatic MM, extra-medullary MM/PCL patients, together with nine HD. Among the 1852 lncRNAs queried by unique probes on the array, 230 were capable to discriminate normal and pathological samples and the different forms of PC dyscrasias. A group of 31 lncRNAs, including MALAT1, was specifically dysregulated in pathological specimens in comparison to normal BM PCs. In addition, the expression of 21 lncRNAs showed a progressive deregulation linked to the aggressiveness of the disease (Figure 1). In particular, Inc-SENP5-4, lnc-CPSF2-2, and lnc-LRRC47-1 displayed a significantly different expression when a group of $19 \mathrm{MMs}$ at diagnosis was matched with the corresponding relapse-PCL phases. Interestingly, the downregulation of $\operatorname{lnc}-L R R C 47-1$ from normal PCs to MGUS and symptomatic myeloma was reported also by others [52]. The panel of 21 lncRNA included GAS5 (growth arrest-specific 5), mapped at 1q25, a tumor suppressor-like associated with cell cycle arrest and apoptosis [53-57]. Interestingly, GAS5 was also significantly upregulated in MMs showing 1q gain, together with other six specific lncRNAs. Patients with del13 had a significant downregulation of DLEU2 (deleted in leukemia 2), mapping at 13q14.3 and hosting the cell cycle inhibitory miRNAs 15a and 16-1 [58]. A significant correlation of DLEU2 with miR-15a and miR-16-1 expression was shown. These findings support a gene-dose effect as a probable mechanism conditioning lncRNAs deregulation.

Finally, Ronchetti et al. expanded their investigation on the function of lncRNA dysregulation in PC dyscrasias by analyzing the association miRNA-lncRNA in MM, PCL, and normal PCs samples. The identification of lncRNA-miRNA pairs (lnc-MCL1-2 and mir-17 gene family; Inc-AGBL1-4 and mir-185-5p; lnc-DLEU2 and miR-3175; LINC00173 and miR-221) with a possible important interplay for MM biology, suggested an influence of miRNA-lncRNA communication on MM pathology [59].

A selection of lncRNAs deregulated in MM with potential relevance in the pathology is reported in Table 1. 


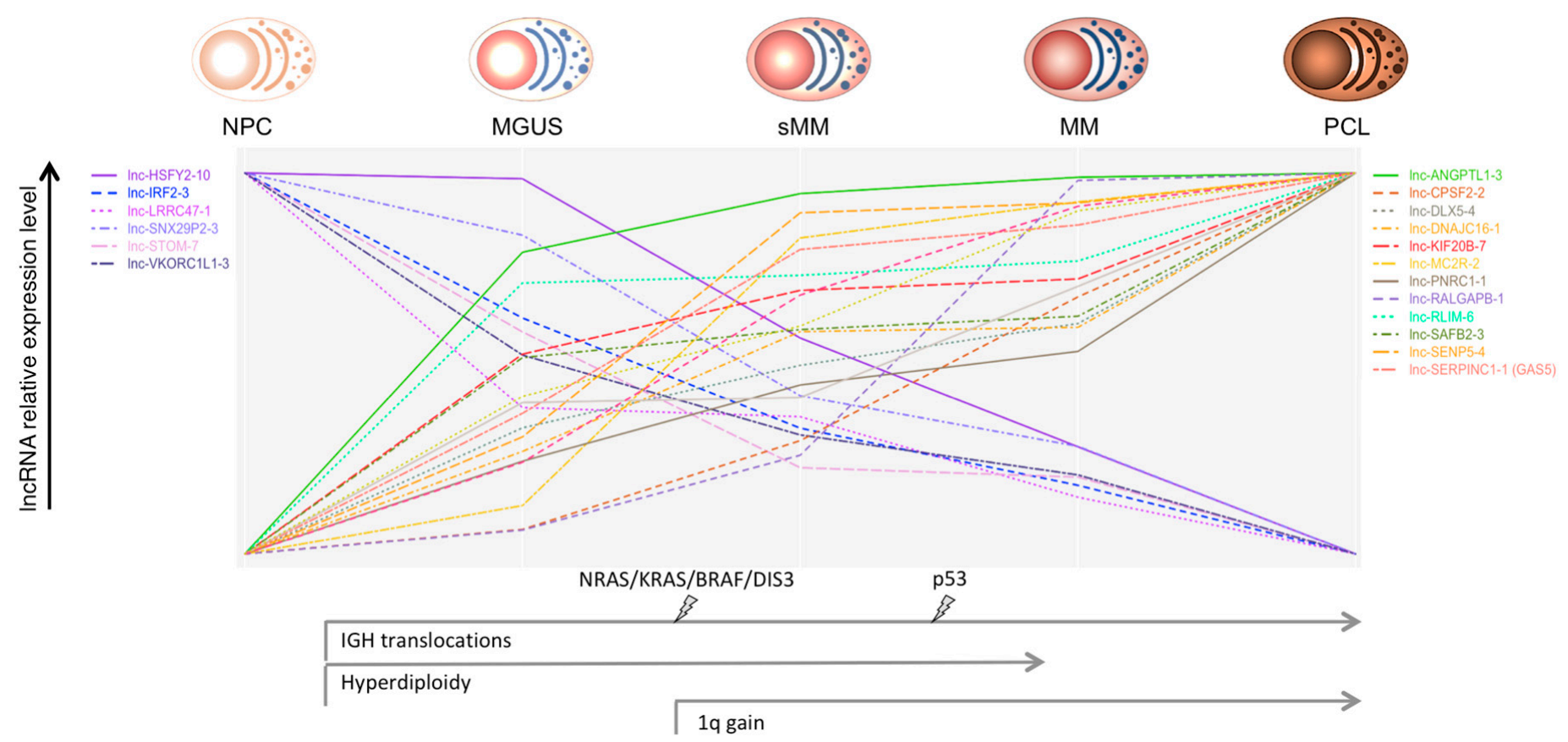

Figure 1. Oncogenic events, such as the main chromosomal aberrations and gene mutations, through the different stages of plasma cell (PC) dyscrasias are represented. The relative expression level (scaled to common y-axis range on the upper and lower values) of the long ncRNAs (lncRNAs) deregulated through the progressive stages of PC dyscrasias is shown [26]. Abbreviations: NPC = normal plasma cell; MGUS = monoclonal gammopathy of undetermined significance; sMM $=$ smoldering multiple myeloma; $\mathrm{MM}=$ multiple myeloma; $\mathrm{PCL}=$ plasma cell leukemia. 
Table 1. Overview of selected lncRNAs with a putative pathogenetic role in multiple myeloma (MM).

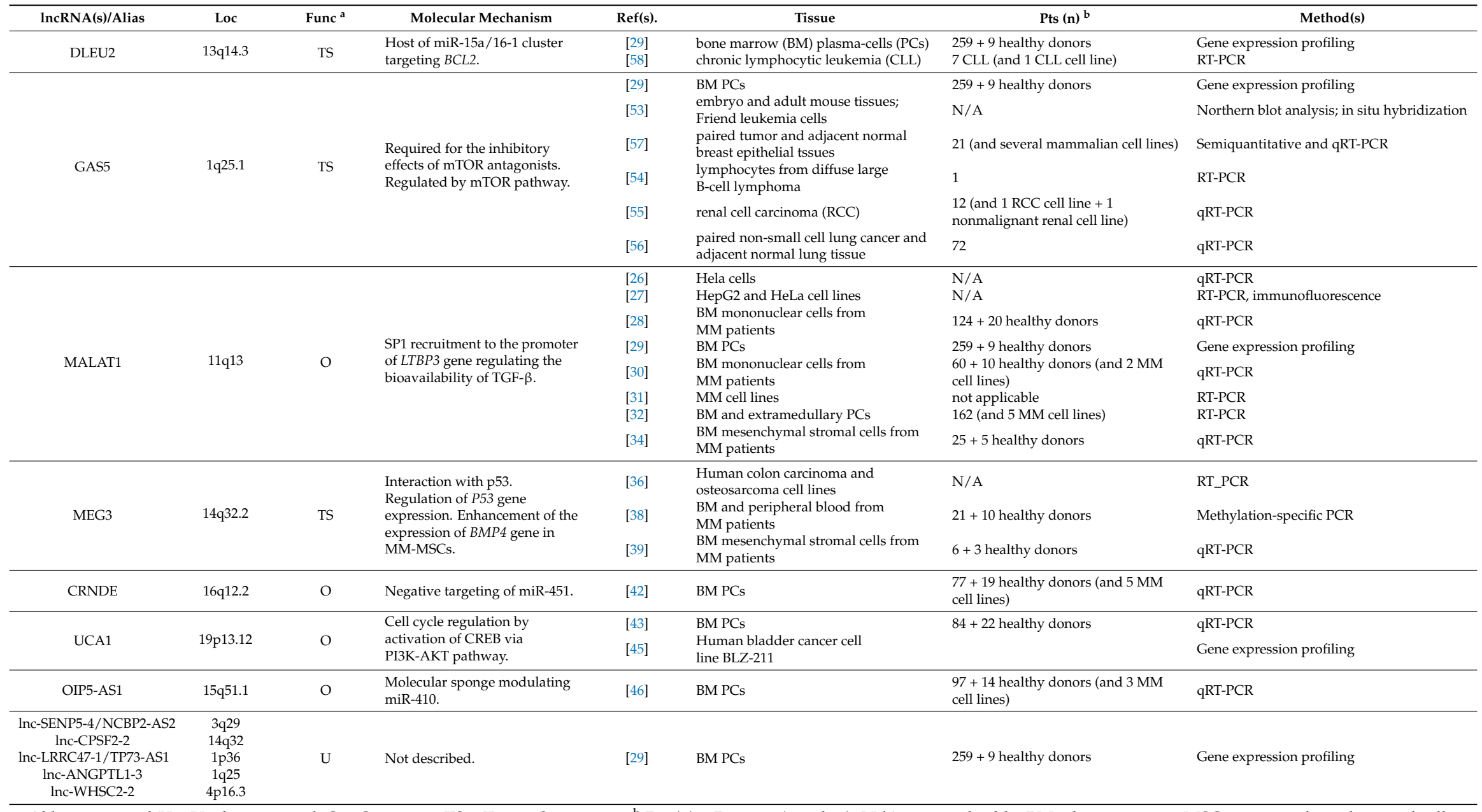

Abbreviations: ${ }^{a} \mathrm{U}=$ Uncharacterized; $\mathrm{O}=$ Oncogene; $\mathrm{TS}=$ Tumor Suppressor; ${ }^{\mathrm{b}}$ Pts $(\mathrm{n})=$ Patients (number). N/A: not applicable. $\mathrm{BM}=$ bone marrow; MSCs = mesenchymal stromal cells 


\section{Conclusions}

LncRNAs are a large and composite family of transcripts that do not encode proteins, with an emergent crucial role in a variety of processes accompanying the biology of normal and cancer cells. Their tissue-specific expression and their easy detectability in body fluids confer them strong potential as biomarkers in the diagnosis and prognosis of many cancer types. The investigation of lncRNAs in MM is still limited, and more extensive profiling studies based on novel approaches, such as RNA sequencing, are needed. In addition, among the dysregulated lncRNAs in MM identified so far, only a few of them have been, at least in part, characterized. However, the available data suggest central roles for lncRNAs in different stages of PC dyscrasias and prompt to explore their relevance as prognostic biomarkers. Furthermore, the targeting of specific lncRNAs in MM have been scarcely investigated until now, hence, a more thorough understanding of their functions and mechanisms in the disease biology is certainly necessary. Improving the knowledge of the types and roles of different lncRNAs in MM will clearly represent a significant step forward in the current comprehension of its pathobiology. Indeed, it would provide valuable information about key cancer-promoting pathways in $\mathrm{MM}$ and be useful for a better diagnostic and prognostic assessment. Furthermore, IncRNA may represent excellent candidates for new anticancer approaches, mostly because of their cancerand tissue-specific expression that could confer major advantages over other therapeutic options. Their better understanding in MM, may provide an important contribution for the development of novel lncRNA-based therapies for the disease.

Acknowledgments: This work was financially supported by grants from Associazione Italiana Ricerca sul Cancro (AIRC) to Antonino Neri (IG16722, IG10136 and the "Special Program Molecular Clinical Oncology-5 per mille" n. 9980, 2010/15).

Author Contributions: L.N., D.R., L.A., E.T., C.V. and A.N. contributed to the final draft and approved the final version of the manuscript.

Conflicts of Interest: The authors declare no conflict of interest.

\section{References}

1. Kuehl, W.M.; Bergsagel, P.L. Multiple myeloma: Evolving genetic events and host interactions. Nat. Rev. Cancer 2002, 2, 175-187. [CrossRef] [PubMed]

2. Kyle, R.A.; Rajkumar, S.V. Monoclonal gammopathies of undetermined significance: A review. Immunol. Rev. 2003, 194, 112-139. [CrossRef] [PubMed]

3. Palumbo, A.; Anderson, K. Multiple myeloma. N. Engl. J. Med. 2011, 364, 1046-1060. [CrossRef] [PubMed]

4. Munshi, N.C.; Anderson, K.C. New strategies in the treatment of multiple myeloma. Clin. Cancer Res. 2013, 19, 3337-3344. [CrossRef] [PubMed]

5. Morgan, G.J.; Walker, B.A.; Davies, F.E. The genetic architecture of multiple myeloma. Nat. Rev. Cancer 2012, 12, 335-348. [CrossRef] [PubMed]

6. Pawlyn, C.; Morgan, G.J. Evolutionary biology of high-risk multiple myeloma. Nat. Rev. Cancer 2017, 17, 543-556. [CrossRef] [PubMed]

7. Neben, K.; Jauch, A.; Hielscher, T.; Hillengass, J.; Lehners, N.; Seckinger, A.; Granzow, M.; Raab, M.S.; Ho, A.D.; Goldschmidt, H.; et al. Progression in smoldering myeloma is independently determined by the chromosomal abnormalities del(17p), t(4;14), gain 1q, hyperdiploidy, and tumor load. J. Clin. Oncol. 2013, 31, 4325-4332. [CrossRef] [PubMed]

8. Zhan, F.; Huang, Y.; Colla, S.; Stewart, J.P.; Hanamura, I.; Gupta, S.; Epstein, J.; Yaccoby, S.; Sawyer, J.; Burington, B.; et al. The molecular classification of multiple myeloma. Blood 2006, 108, 2020-2028. [CrossRef] [PubMed]

9. Birney, E.; Stamatoyannopoulos, J.A.; Dutta, A.; Guigo, R.; Gingeras, T.R.; Margulies, E.H.; Weng, Z.; Snyder, M.; Dermitzakis, E.T;; Thurman, R.E.; et al. Identification and analysis of functional elements in $1 \%$ of the human genome by the ENCODE pilot project. Nature 2007, 447, 799-816. [CrossRef] [PubMed]

10. Djebali, S.; Davis, C.A.; Merkel, A.; Dobin, A.; Lassmann, T.; Mortazavi, A.; Tanzer, A.; Lagarde, J.; Lin, W.; Schlesinger, F.; et al. Landscape of transcription in human cells. Nature 2012, 489, 101-108. [CrossRef] [PubMed] 
11. Kong, Y.W.; Ferland-McCollough, D.; Jackson, T.J.; Bushell, M. microRNAs in cancer management. Lancet Oncol. 2012, 13, e249-e258. [CrossRef]

12. Berindan-Neagoe, I.; Monroig Pdel, C.; Pasculli, B.; Calin, G.A. MicroRNAome genome: A treasure for cancer diagnosis and therapy. CA Cancer J. Clin. 2014, 64, 311-336. [CrossRef] [PubMed]

13. Garzon, R.; Marcucci, G.; Croce, C.M. Targeting microRNAs in cancer: Rationale, strategies and challenges. Nat. Rev. Drug Discov. 2010, 9, 775-789. [CrossRef] [PubMed]

14. Amodio, N.; Di Martino, M.T.; Neri, A.; Tagliaferri, P.; Tassone, P. Non-coding RNA: A novel opportunity for the personalized treatment of multiple myeloma. Expert Opin. Biol. Ther. 2013, 13 (Suppl. S1), S125-S137. [CrossRef] [PubMed]

15. Cabili, M.N.; Trapnell, C.; Goff, L.; Koziol, M.; Tazon-Vega, B.; Regev, A.; Rinn, J.L. Integrative annotation of human large intergenic noncoding RNAs reveals global properties and specific subclasses. Genes Dev. 2011, 25, 1915-1927. [CrossRef] [PubMed]

16. Lee, J.T. Epigenetic regulation by long noncoding RNAs. Science 2012, 338, 1435-1439. [CrossRef] [PubMed]

17. Volders, P.J.; Verheggen, K.; Menschaert, G.; Vandepoele, K.; Martens, L.; Vandesompele, J.; Mestdagh, P. An update on LNCipedia: A database for annotated human lncRNA sequences. Nucleic Acids Res. 2015, 43, D174-D180. [CrossRef] [PubMed]

18. Fang, S.; Zhang, L.; Guo, J.; Niu, Y.; Wu, Y.; Li, H.; Zhao, L.; Li, X.; Teng, X.; Sun, X.; et al. NONCODEV5: A comprehensive annotation database for long non-coding RNAs. Nucleic Acids Res. 2018, 46, D308-D314. [CrossRef] [PubMed]

19. Wapinski, O.; Chang, H.Y. Long noncoding RNAs and human disease. Trends Cell Biol. 2011, $21,354-361$. [CrossRef] [PubMed]

20. Hung, T.; Chang, H.Y. Long noncoding RNA in genome regulation: Prospects and mechanisms. RNA Biol. 2010, 7, 582-585. [CrossRef] [PubMed]

21. Poliseno, L.; Salmena, L.; Zhang, J.; Carver, B.; Haveman, W.J.; Pandolfi, P.P. A coding-independent function of gene and pseudogene mRNAs regulates tumour biology. Nature 2010, 465, 1033-1038. [CrossRef] [PubMed]

22. Geisler, S.; Coller, J. RNA in unexpected places: Long non-coding RNA functions in diverse cellular contexts. Nat. Rev. Mol. Cell Biol. 2013, 14, 699-712. [CrossRef] [PubMed]

23. Wang, K.C.; Chang, H.Y. Molecular mechanisms of long noncoding RNAs. Mol. Cell 2011, 43, $904-914$. [CrossRef] [PubMed]

24. Mercer, T.R.; Mattick, J.S. Structure and function of long noncoding RNAs in epigenetic regulation. Nat. Struct. Mol. Biol. 2013, 20, 300-307. [CrossRef] [PubMed]

25. Silva, A.; Bullock, M.; Calin, G. The Clinical Relevance of Long Non-Coding RNAs in Cancer. Cancers 2015, 7, 2169-2182. [CrossRef] [PubMed]

26. Tripathi, V.; Ellis, J.D.; Shen, Z.; Song, D.Y.; Pan, Q.; Watt, A.T.; Freier, S.M.; Bennett, C.F.; Sharma, A.; Bubulya, P.A.; et al. The nuclear-retained noncoding RNA MALAT1 regulates alternative splicing by modulating SR splicing factor phosphorylation. Mol. Cell 2010, 39, 925-938. [CrossRef] [PubMed]

27. Yang, F.; Yi, F.; Han, X.; Du, Q.; Liang, Z. MALAT-1 interacts with hnRNP C in cell cycle regulation. FEBS Lett. 2013, 587, 3175-3181. [CrossRef] [PubMed]

28. Cho, S.F.; Chang, Y.C.; Chang, C.S.; Lin, S.F.; Liu, Y.C.; Hsiao, H.H.; Chang, J.G.; Liu, T.C. MALAT1 long non-coding RNA is overexpressed in multiple myeloma and may serve as a marker to predict disease progression. BMC Cancer 2014, 14, 809. [CrossRef] [PubMed]

29. Ronchetti, D.; Agnelli, L.; Taiana, E.; Galletti, S.; Manzoni, M.; Todoerti, K.; Musto, P.; Strozzi, F.; Neri, A. Distinct lncRNA transcriptional fingerprints characterize progressive stages of multiple myeloma. Oncotarget 2016, 7, 14814-14830. [CrossRef] [PubMed]

30. Gao, D.; Xiao, Z.; Li, H.P.; Han, D.H.; Zhang, Y.P. LncRNA MALAT-1 Elevates HMGB1 to Promote Autophagy Resulting in Inhibition of Tumor Cell Apoptosis in Multiple Myeloma. J. Cell. Biochem. 2017, 118, 3341-3348. [CrossRef] [PubMed]

31. Liu, H.; Wang, H.; Wu, B.; Yao, K.; Liao, A.; Miao, M.; Li, Y.; Yang, W. Down-regulation of long noncoding RNA MALAT1 by RNA interference inhibits proliferation and induces apoptosis in multiple myeloma. Clin. Exp. Pharmacol. Physiol. 2017, 44, 1032-1041. [CrossRef] [PubMed] 
32. Handa, H.; Kuroda, Y.; Kimura, K.; Masuda, Y.; Hattori, H.; Alkebsi, L.; Matsumoto, M.; Kasamatsu, T.; Kobayashi, N.; Tahara, K.I.; et al. Long non-coding RNA MALAT1 is an inducible stress response gene associated with extramedullary spread and poor prognosis of multiple myeloma. Br. J. Haematol. 2017, 179, 449-460. [CrossRef] [PubMed]

33. Roy, M.; Liang, L.; Xiao, X.; Peng, Y.; Luo, Y.; Zhou, W.; Zhang, J.; Qiu, L.; Zhang, S.; Liu, F.; et al. Lycorine Downregulates HMGB1 to Inhibit Autophagy and Enhances Bortezomib Activity in Multiple Myeloma. Theranostics 2016, 6, 2209-2224. [CrossRef] [PubMed]

34. Li, B.; Chen, P.; Qu, J.; Shi, L.; Zhuang, W.; Fu, J.; Li, J.; Zhang, X.; Sun, Y.; Zhuang, W. Activation of LTBP3 gene by a long noncoding RNA (lncRNA) MALAT1 transcript in mesenchymal stem cells from multiple myeloma. J. Biol. Chem. 2014, 289, 29365-29375. [CrossRef] [PubMed]

35. Matsumoto, T.; Abe, M. TGF-beta-related mechanisms of bone destruction in multiple myeloma. Bone 2011, 48, 129-134. [CrossRef] [PubMed]

36. Zhou, Y.; Zhong, Y.; Wang, Y.; Zhang, X.; Batista, D.L.; Gejman, R.; Ansell, P.J.; Zhao, J.; Weng, C.; Klibanski, A. Activation of p53 by MEG3 non-coding RNA. J. Biol. Chem. 2007, 282, 24731-24742. [CrossRef] [PubMed]

37. Haertle, L.; Maierhofer, A.; Bock, J. Hypermethylation of the non-imprinted maternal MEG3 and paternal MEST alleles is highly variable among normal individuals. PLoS ONE 2017, 12, e0184030. [CrossRef] [PubMed]

38. Benetatos, L.; Dasoula, A.; Hatzimichael, E.; Georgiou, I.; Syrrou, M.; Bourantas, K.L. Promoter hypermethylation of the MEG3 (DLK1/MEG3) imprinted gene in multiple myeloma. Clin. Lymphoma Myeloma 2008, 8, 171-175. [CrossRef] [PubMed]

39. Zhuang, W.; Ge, X.; Yang, S.; Huang, M.; Zhuang, W.; Chen, P.; Zhang, X.; Fu, J.; Qu, J.; Li, B. Upregulation of lncRNA MEG3 Promotes Osteogenic Differentiation of Mesenchymal Stem Cells from Multiple Myeloma Patients By Targeting BMP4 Transcription. Stem Cells 2015, 33, 1985-1997. [CrossRef] [PubMed]

40. Graham, L.D.; Pedersen, S.K.; Brown, G.S.; Ho, T.; Kassir, Z.; Moynihan, A.T.; Vizgoft, E.K.; Dunne, R.; Pimlott, L.; Young, G.P.; et al. Colorectal Neoplasia Differentially Expressed (CRNDE), a Novel Gene with Elevated Expression in Colorectal Adenomas and Adenocarcinomas. Genes Cancer 2011, 2, 829-840. [CrossRef] [PubMed]

41. Ellis, B.C.; Molloy, P.L.; Graham, L.D. CRNDE: A Long Non-Coding RNA Involved in CanceR, Neurobiology, and DEvelopment. Front. Genet. 2012, 3, 270. [CrossRef] [PubMed]

42. Meng, Y.B.; He, X.; Huang, Y.F.; Wu, Q.N.; Zhou, Y.C.; Hao, D.J. Long Non-coding RNA CRNDE Promotes Multiple Myeloma Cell Growth By Suppressing MiR-451. Oncol. Res. 2017, 25, 1207-1214. [CrossRef] [PubMed]

43. Sedlarikova, L.; Gromesova, B.; Kubaczkova, V.; Radova, L.; Filipova, J.; Jarkovsky, J.; Brozova, L.; Velichova, R.; Almasi, M.; Penka, M.; et al. Deregulated expression of long non-coding RNA UCA1 in multiple myeloma. Eur. J. Haematol. 2017, 99, 223-233. [CrossRef] [PubMed]

44. Wang, X.S.; Zhang, Z.; Wang, H.C.; Cai, J.L.; Xu, Q.W.; Li, M.Q.; Chen, Y.C.; Qian, X.P.; Lu, T.J.; Yu, L.Z.; et al. Rapid identification of UCA1 as a very sensitive and specific unique marker for human bladder carcinoma. Clin. Cancer Res. 2006, 12, 4851-4858. [CrossRef] [PubMed]

45. Yang, C.; Li, X.; Wang, Y.; Zhao, L.; Chen, W. Long non-coding RNA UCA1 regulated cell cycle distribution via CREB through PI3-K dependent pathway in bladder carcinoma cells. Gene 2012, 496, 8-16. [CrossRef] [PubMed]

46. Yang, N.; Chen, J.; Zhang, H.; Wang, X.; Yao, H.; Peng, Y.; Zhang, W. LncRNA OIP5-AS1 loss-induced microRNA-410 accumulation regulates cell proliferation and apoptosis by targeting KLF10 via activating PTEN/PI3K/AKT pathway in multiple myeloma. Cell Death Dis. 2017, 8, e2975. [CrossRef] [PubMed]

47. Zhou, M.; Zhao, H.; Wang, Z.; Cheng, L.; Yang, L.; Shi, H.; Yang, H.; Sun, J. Identification and validation of potential prognostic lncRNA biomarkers for predicting survival in patients with multiple myeloma. J. Exp. Clin. Cancer Res. 2015, 34, 102. [CrossRef] [PubMed]

48. Hu, A.X.; Huang, Z.Y.; Zhang, L.; Shen, J. Potential prognostic long non-coding RNA identification and their validation in predicting survival of patients with multiple myeloma. Tumour Biol. 2017, 39. [CrossRef] [PubMed]

49. Shaughnessy, J.D., Jr.; Zhan, F.; Burington, B.E.; Huang, Y.; Colla, S.; Hanamura, I.; Stewart, J.P.; Kordsmeier, B.; Randolph, C.; Williams, D.R.; et al. A validated gene expression model of high-risk multiple myeloma is defined by deregulated expression of genes mapping to chromosome 1. Blood 2007, 109, 2276-2284. [CrossRef] [PubMed] 
50. Hebraud, B.; Leleu, X.; Lauwers-Cances, V.; Roussel, M.; Caillot, D.; Marit, G.; Karlin, L.; Hulin, C.; Gentil, C.; Guilhot, F.; et al. Deletion of the 1p32 region is a major independent prognostic factor in young patients with myeloma: The IFM experience on 1195 patients. Leukemia 2014, 28, 675-679. [CrossRef] [PubMed]

51. Chng, W.J.; Gertz, M.A.; Chung, T.H.; Van Wier, S.; Keats, J.J.; Baker, A.; Bergsagel, P.L.; Carpten, J.; Fonseca, R. Correlation between array-comparative genomic hybridization-defined genomic gains and losses and survival: Identification of 1p31-32 deletion as a prognostic factor in myeloma. Leukemia 2010, 24, 833-842. [CrossRef] [PubMed]

52. Wong, K.Y.; Li, Z.; Zhang, X.; Leung, G.K.; Chan, G.C.; Chim, C.S. Epigenetic silencing of a long non-coding RNA KIAA0495 in multiple myeloma. Mol. Cancer 2015, 14, 175. [CrossRef] [PubMed]

53. Coccia, E.M.; Cicala, C.; Charlesworth, A.; Ciccarelli, C.; Rossi, G.B.; Philipson, L.; Sorrentino, V. Regulation and expression of a growth arrest-specific gene (gas5) during growth, differentiation, and development. Mol. Cell. Biol. 1992, 12, 3514-3521. [CrossRef] [PubMed]

54. Nakamura, Y.; Takahashi, N.; Kakegawa, E.; Yoshida, K.; Ito, Y.; Kayano, H.; Niitsu, N.; Jinnai, I.; Bessho, M. The GAS5 (growth arrest-specific transcript 5) gene fuses to BCL6 as a result of $t(1 ; 3)(q 25 ; q 27)$ in a patient with B-cell lymphoma. Cancer Genet. Cytogenet. 2008, 182, 144-149. [CrossRef] [PubMed]

55. Qiao, H.P.; Gao, W.S.; Huo, J.X.; Yang, Z.S. Long non-coding RNA GAS5 functions as a tumor suppressor in renal cell carcinoma. Asian Pac. J. Cancer Prev. 2013, 14, 1077-1082. [CrossRef] [PubMed]

56. Shi, X.; Sun, M.; Liu, H.; Yao, Y.; Kong, R.; Chen, F.; Song, Y. A critical role for the long non-coding RNA GAS5 in proliferation and apoptosis in non-small-cell lung cancer. Mol. Carcinog. 2015, 54 (Suppl. S1), e1-e12. [CrossRef] [PubMed]

57. Mourtada-Maarabouni, M.; Pickard, M.R.; Hedge, V.L.; Farzaneh, F; Williams, G.T. GAS5, a non-protein-coding RNA, controls apoptosis and is downregulated in breast cancer. Oncogene 2009, 28, 195-208. [CrossRef] [PubMed]

58. Lerner, M.; Harada, M.; Loven, J.; Castro, J.; Davis, Z.; Oscier, D.; Henriksson, M.; Sangfelt, O.; Grander, D.; Corcoran, M.M. DLEU2, frequently deleted in malignancy, functions as a critical host gene of the cell cycle inhibitory microRNAs miR-15a and miR-16-1. Exp. Cell Res. 2009, 315, 2941-2952. [CrossRef] [PubMed]

59. Ronchetti, D.; Manzoni, M.; Todoerti, K.; Neri, A.; Agnelli, L. In Silico Characterization of miRNA and Long Non-Coding RNA Interplay in Multiple Myeloma. Genes 2016, 7, 107. [CrossRef] [PubMed]

(C) 2018 by the authors. Licensee MDPI, Basel, Switzerland. This article is an open access article distributed under the terms and conditions of the Creative Commons Attribution (CC BY) license (http:/ / creativecommons.org/licenses/by/4.0/). 